\title{
Factors Affecting the Thermal Stability of Polytetrafluoroethylene ${ }^{1}$
}

\author{
R. E. Florin, L. A. Wall, D. W. Brown, L. A. Hymo, and J. D. Michaelsen
}

\begin{abstract}
The structure and kinetics of thermal decomposition of polytetrafluoroethylene suggested several methods for improvement of its stability: (a) polymerization in the presence of fluorocarbon catalysts or photochemically to eliminate labile centers for initiation, (b) inclusion of foreign structural units in the polvmer to promote chain transfer of the free radicals active in depolymerization, (c) inclusion of foreign molecules capable of promoting chain transfer. The catalysts tried included perfluorodimethylmercury, perfluoromethyl iodide, and fluorine gas, as well as conventional catalysts. The foreign structural units and additives included sulfur, selenium, and a variety of hydrocarbon and fluorocarbon groups, mainly aromatic, added usually as dibromides to the polymerizing mixture. None of the experimental catalysts or additives brought about any change in the rate of thermal decomposition.
\end{abstract}

\section{Introduction}

A search for polymers for use at high temperatures may naturally begin with polytetrafluoroethylene, which is the most stable of known polymers. The commercial material, Teflon, is somewhat limited in structural applications by a physical transition occurring at $327^{\circ} \mathrm{C}$, but it does not undergo rapid thermal decomposition below about $450^{\circ} \mathrm{C}$. Even a moderate improvement in the thermal stability of this polymer, for example, raising the decomposition temperature range by $50^{\circ}$ to $100^{\circ} \mathrm{C}$ or the creation of an induction period, would adapt it to new uses.

It is not likely that any organic or semiorganic polymer will be stable in the thermodynamic sense at $500^{\circ} \mathrm{C}$. Hence, any hope for improvement in the thermal stability can arise only from kinetic or mechanistic considerations. Such an approach has decided possibilities.

The thermal decomposition of ordinary polytetrafluoroethylene has certain other peculiarities, aside from the high temperature at which it occurs. The polymer does not melt, but decomposes in a solid or extremely viscous mass. This situation could extend the lifetime of the free radicals responsible for decomposition. Also, because of the regular structure, containing only strong $\mathrm{C}-\mathrm{F}$ and $\mathrm{C}-\mathrm{C}$ bonds, there is no opportunity for chaintransfer reactions; as one consequence, the depolymerization of a given radical proceeds without interruption, to yield monomer almost exclusively.

To increase the thermal stability, three different mechanistic possibilities can be considered.

1. Elimination of possible impurities, i. e., nonfluorocarbon end-groups at which the depolymerization may be initiated.

2 . Inclusion of structures in the chain designed to hinder or stop the depropagation reaction, by which monomer units are stripped from a free radical. These structures would produce a random type of 1 This work was performed as part of the research project on high-temperature-
resistant polymers sponsored by the Ordnance Corps, Department of the Army. degradation, which should result in an induction period. The effect could be enhanced if the concomitant reactions also produced cross links.

3. Inclusion of a mobile material to terminate radicals. The lifetime of the free radicals in polytetrafluoroethylene pyrolysis may be unduly long because of their immobility. If sufficiently mobile agents could reach these radicals, and terminate them wholly or in part, a more stable polymer should result.

To explore these possibilities, a number of tetrafluoroethylene polymers were prepared, using conditions and catalysts chosen to give a polymer as free as possible from thermally labile end-groups. Some conventional catalysts were also used for comparison. In addition, a number of materials were added which might either enter the polymer chain as structural units, or be intimately incorporrated in the polymer mass. The degradation of the resulting polymers was studied and rates compared.

\section{Polymerization of Tetrafluoroethylene}

Polytetrafluoroethylene was discovered in 1946 by Plunkett [1]. ${ }^{2}$ The polymerization of tetrafluoroethylene is similar in principle to that of most vinyl monomers, and appears to proceed by a free-radical chain mechanism. A schematic summary of the principal steps in the reaction is

Initiation:

or

$$
\underset{\text { (catalytic) }}{\text { Catalyst }}
$$

Monomer $\longrightarrow$ radical (photochemical or thermal)

Propagation:]

$$
\begin{gathered}
\text { Radical }+ \text { monomer } \longrightarrow \text { larger radical } \\
\mathrm{R} \cdot+\mathrm{CX}_{2}=\mathrm{CX}_{2} \longrightarrow \mathrm{RCX}_{2} \mathrm{CX}_{2} .
\end{gathered}
$$

${ }_{2}$ Figures in brackets indicate the literature references at the end of this paper. 
Here the R. may be derived from catalyst or monomer, the X's may be like or unlike atoms or groups, depending on the monomer formula, and the step is repeated many times until a high molecular weight is reached.

Termination:

$$
\begin{aligned}
& \text { Radical+radical } \longrightarrow \text { polymer } \\
& \mathrm{R}\left(\mathrm{CX}_{2} \mathrm{CX}_{2}\right)_{i}+\mathrm{R}\left(\mathrm{CX}_{2} \mathrm{CX}_{2}\right)_{j^{*}} \longrightarrow \mathrm{R}\left(\mathrm{CX}_{2} \mathrm{CX}_{2}\right)_{i+j} \mathrm{R}
\end{aligned}
$$

or

$$
\begin{aligned}
& \text { Radical+radical } \longrightarrow 2 \text { polymer } \\
& \mathrm{R}\left(\mathrm{CX}_{2} \mathrm{CX}_{2}\right)_{i^{*}}+\mathrm{R}\left(\mathrm{CX}_{2} \mathrm{CX}_{2}\right)_{j} \longrightarrow \\
& \mathrm{R}\left(\mathrm{CX}_{2} \mathrm{CX}_{2}\right)_{i-1} \mathrm{CX}_{2} \mathrm{CX}_{3}+\mathrm{R}\left(\mathrm{CX}_{2} \mathrm{CX}_{2}\right)_{j-1} \mathrm{CX}=\mathrm{CX}_{2}
\end{aligned}
$$

Transfer:

$$
\mathrm{R}\left(\mathrm{CX}_{2} \mathrm{CX}_{2}\right)_{i^{*}}+\mathrm{RCX}_{2} \mathrm{R} \longrightarrow \mathrm{RCX}_{2} \mathrm{CX}_{3}+\mathrm{RCXR} .
$$

If inhibitors are present, they may combine with the radicals to form molecules or unreactive radicals.

Some reactions are known that share most of the features given but have an over-all equation:

$$
\mathrm{YZ}+n \mathrm{CX}_{2}=\mathrm{CX}_{2} \longrightarrow \mathrm{Y}\left(\mathrm{CX}_{2} \mathrm{CX}_{2}\right)_{n} \mathrm{Z}
$$

Such a reaction is called telomerization. The distinction is most important when $n$ is small.

Common methods of polymerizing tetrafluoroethylene are indicated by Hanford and Joyce [2]. As catalysts, hydrogen peroxide, oxygen, persulfates, and several organic peroxides are disclosed. Conditions in the range 0 to $100^{\circ} \mathrm{C}$ and 15 to over 1,000 $\mathrm{lb} /$ in. $^{2}$ are covered. As a typical example, monomer is introduced at $700 \mathrm{lb} / \mathrm{in}^{2}{ }^{2}$ into a reactor containing a large amount of water solution of catalyst. Agitation at $60^{\circ} \mathrm{C}$ produces a nearly complete conversion to polymer in 17 hours. To avoid explosions, it is important to remove rapidly the heat developed.

In the laboratory, Atkinson [3] studied the mercury-sensitized photochemical reactions of tetrafluoroethylene in the gas phase at room temperature and low pressures. He found large amount of hexafluorocyclopropane produced, as well as high polymer, and found that polymer once formed seemed to catalyze the formation of both products but especially of more polymer. His results led him to stress the part played by $\cdot \mathrm{CF}_{2}$. radicals. The quantum yield was 0.02 to 0.2 for production of $\mathrm{C}_{3} \mathrm{~F}_{6}\left(\mathrm{C}_{2} \mathrm{~F}_{4}\right.$ consumed divided by 3 times quanta absorbed) and about 0.2 for production of polymer (molecules $\mathrm{C}_{2} \mathrm{~F}_{4}$ polymerized divided by quanta absorbed).

Raal and Danby [4], in gas-phase photochemical experiments at about $300^{\circ} \mathrm{C}$ and low pressures, found that tetrafluoroethylene was polymerized by methyl radicals derived from the photolysis of acetone and acetaldehyde; the estimated chain length was
26 units of tetrafluoroethylene polymerized per molecule of acetaldehyde decomposed. The tetrafluoroethylene accelerated the decomposition of acetaldehyde but not of acetone.

Haszeldine [5] produced telomers $\mathrm{CF}_{3}\left(\mathrm{CF}_{2} \mathrm{CF}_{2}\right)_{n} \mathrm{I}$ containing up to $10 \quad \mathrm{C}_{2} \mathrm{~F}_{4}$ units by thermal and photochemical reaction of mixtures containing rather large amounts of iodotrifluoromethane.

Berry and Peterson [6] polymerized tetrafluoroethylene in the presence of radioactive sulfur compounds to secure an estimate of the molecular weight of the polymer. The molecular weight of polytetrafluoroethylene has never been measured directly, because no solvent for this polymer is known. The investigators sought an indirect estimate based upon radioactive measurement of sulfur incorporated in the polymer and the reasonable assumption that each polymer molecule should contain two sulfur atoms. Using redox recipes, they found that with radioactive persulfate catalyst, no radioactive sulfur appears in the polymer isolated, but that with radioactive bisulfite in a recipe containing various other components, sulfur was incorporated and was not removable by prolonged heating with water. Their calculations led to a molecular weight of 142,000 to 534,000 for their polytetrafluoroethylene. They suggest that the polymer end-groups derived from their bisulfite are sulfonic acid groups $-\mathrm{SO}_{3} \mathrm{H}$, and that the polymer ordinarily prepared with persulfate catalyst may contain carboxylic acid endgroups, - $\mathrm{COOH}$.

Von Grosse and Cady [7] report that tetrafluoroethylene is polymerized by boron fluoride and niobium pentafluoride. The niobium pentafluoride polymerization was reported to resemble the action of aluminum chloride on ethylene, i. e., a rapid reaction leading to low molecular weights; the boron fluoride reaction was reported to proceed slowly, yielding in several days at room temperature a high polymer resembling Teflon.

It is evident that most of the catalytic methods may introduce end-groups of lower stability into the polymer molecule, for example, hydrocarbon fragments from organic peroxides, $-\mathrm{COOH}$ indirectly from persulfate, and possibly - $\mathrm{O}-\mathrm{O}$ - from molecular oxygen. To avoid molecular oxygen and for general convenience, it was found useful to employ a vacuum-line technique, and ordinarily to polymerize the monomer in liquid phase in quartz tubes at low temperature, with activation of catalysts by ultraviolet light. Some catalysts that might avoid the introduction of thermally labile end-groups were investigated in the research described in this paper.

\subsection{Materials Used in Investigation}

Tetrafluoroethylene. Most of the monomer was prepared by pyrolysis of Teflon polymer at $650^{\circ}$ to $700^{\circ} \mathrm{C}$ and $1 \mathrm{~mm}$, using the method of Lewis and Naylor [8] with minor changes. Contrary to expectations based upon the results of these authors at moderate pressures, a small percentage of higher fluorocarbons appears to form even at pressures of 
a few microns [9]. In distilling the monomer into polymerization tubes, a small tail fraction, roughly 20 percent, was rejected. Typical monomer contained traces of higher fluorocarbons and very little of hydrogen compounds.

For comparison, a small lot was also prepared by pyrolysis of pure sodium perfluoropropionate, obtained from the Minnesota Mining \& Manufacturing Co. [10]. The gaseous product was scrubbed with $4 N$ sodium hydroxide to remove carbon dioxide and large head and tail fractions were rejected in subsequent distillation. Mass spectrometer analyses of the two preparations of monomer appear in table 1.

The monomer, after distillation in vacuum into the polymerization tubes, was degassed by melting in dry ice, refreezing in liquid nitrogen, and pumping in succession. Usually 4 or 5 degassing cycles were necessary to achieve a pressure of about 0.2 micron. After such degassing, a sample of monomer contained less than $1 \mathrm{ppm}$ of $\mathrm{O}_{3}$.

Special samples were also treated by distilling into 1-liter bulbs coated with sodium or potassium mirrors and having the polymerization tube sealed to a side arm; degassing as usual; sealing off and holding the gaseous monomer in contact with the mirror at room temperature for 10 days; and subsequently condensing into the polymerization tube.

Perfluoromethyl iodide, $\mathrm{CF}_{2} \mathrm{I}$, was prepared by heating a mixture of silver trifluoroacetate and iodine [11]. The product was used after a simple distillation.

TABLE 1. Mass-spectrometer analyses of tetrafluoroethylene

\begin{tabular}{|c|c|c|}
\hline & Constituent & $\begin{array}{l}\text { Fraction of } \\
\text { the sample }\end{array}$ \\
\hline From pyrolysis of Teflon... & $\left\{\begin{array}{l}\mathrm{C}_{2} \mathrm{~F}_{4} \\
\mathrm{C}_{2} \mathrm{~F}_{6} \\
\mathrm{C}_{3} \mathrm{~F}_{6} \\
\mathrm{C}_{4} \mathrm{~F}_{8} \\
\mathrm{CO}_{2}\end{array}\right.$ & $\begin{array}{l}\text { Mole \% } \\
95.0 \\
0.1 \\
4.5 \\
0.3 \\
.1\end{array}$ \\
\hline $\begin{array}{l}\text { From pyrolysis of Teflon; } \\
\text { degassed }\end{array}$ & $\left\{\begin{array}{l}\mathrm{O}_{2} \\
\mathrm{H}_{2} \mathrm{O}, \mathrm{A}, \mathrm{N}_{2}, \mathrm{CO}_{2}, \mathrm{CH}_{4} \text { : detected, } \\
\text { uncertain whether from sam- } \\
\text { ple or connecting tube. }\end{array}\right.$ & $0.3 \mathrm{ppm}$ \\
\hline $\begin{array}{l}\text { From } \mathrm{CF}_{3} \mathrm{CF}_{2} \mathrm{CO}_{2} \mathrm{Na} ; \\
\text { crude }\end{array}$ & $\left\{\begin{array}{l}\mathrm{C}_{2} \mathrm{~F}_{4} \\
\mathrm{C}_{2} \mathrm{~F}_{6} \\
\mathrm{CO}_{2} \\
\text { Hydrogenated fluorocarbons: } \\
\text { Mass } 51,1.8 \%, \text { also mass } 101 .\end{array}\right.$ & $\begin{array}{l}\text { Mole \% } \\
92.5 \\
0.6 \\
6.9 \\
\end{array}$ \\
\hline $\begin{array}{l}\text { From } \mathrm{CF}_{3} \mathrm{CF}_{2} \mathrm{CO}_{2} \mathrm{Na} \text {; un- } \\
\text { reacted monomer from } \\
\text { opened polymerization } \\
\text { tube (expt.4) }\end{array}$ & $\left\{\begin{array}{l}\mathrm{C}_{2} \mathrm{~F}_{4} \\
\mathrm{CO}_{2} \\
\mathrm{O}_{2} \\
\mathrm{~N}_{2} \\
\text { Mass } 131 \text { (possibly } \mathrm{C}_{3} \mathrm{~F}_{5}+\text { ) } 0.06 .\end{array}\right.$ & $\begin{array}{l}\text { Mole \% } \\
97.3 \\
1.1 \\
1.4 \\
1.2 \\
-\end{array}$ \\
\hline
\end{tabular}

1 The $\mathrm{N}_{2}, \mathrm{O}_{2}$, and probably $\mathrm{CO}_{2}$ were introduced during opening of the tube.

Diperfluoromethylmercury, $\left(\mathrm{CF}_{3}\right)_{2} \mathrm{Hg}$, was made from iodotrifluoromethane and cadmium amalgam. ${ }^{3}$ The resublimed product was used [12].

Fluorine was the product of Pennsylvania Salt Manufacturing Co. The manufacturer's analysis shows $\mathrm{F}_{2}, 96.6$ percent; $\mathrm{HF}, 0.6$ percent; and $\mathrm{O}_{2}, 2.8$

3 Iodotrifluoromethane and diperfluoromethylmercury were prepared by A. J. Bilbo of the Bureau's Polymer Structure Section. percent. The mass spectrometer indicated traces of fluorocarbons.

Azo-bis (isobutyronitrile) was a sample furnished by Rohm \& Hass Co.

1, 2, 4, 5-Tetrafluoro-3, 6-dibromobenzene was prepared at the Bureau by a syntheses reported elsewhere [13].

Other materials were, in general, commercially pure grades.

\subsection{Apparatus and Methods}

Polymerization tubes were usually of quartz, of 1-mm wall thickness, $10-\mathrm{mm}$ inside diameter, and about $150-\mathrm{mm}$ length. In many of the experiments with dibromide additives, thick-walled quartz tubes of 2- to $3-\mathrm{mm}$ wall thickness, and otherwise similar dimensions were used. A few experiments were made in Vycor 790 tubes of about 3-mm wall thickness and 19-mm-inside diameter, and, where illumination was not desired, in thick-walled Pyrex. Tubes were filled, degassed, and sealed on the vacuum line. Monomer was weighed by difference or measured as gas. Nonvolatile materials, such as most catalysts, were weighed. Gases such as iodotrifluoromethane and boron fluoride were measured in bulbs.

Most of the polymerizations were done in a cold block, which allowed the samples to be held at a roughly controlled low temperature while exposed to ultraviolet irradiation. The block, of aluminum alloy, was partly immersed in liquid nitrogen. Cold nitrogen gas flowed upward through a central hole in which the polymerization tube and a thermocouple were supported. A slot $6 \mathrm{~mm}$ wide allowed irradiation from a high-pressure mercury lamp, located at a distance of $10 \mathrm{~cm}$. As the equipment was designed for intensity of illumination and flexibility, rather than for reproducibility of conditions, the observations on polymerization rates should be accepted with caution. The equipment gave reasonably good constancy of temperature with time, adjustments seldom being necessary oftenor than at 5 -minute intervals. The variation from top to bottom of the tube was of the order of $20^{\circ} \mathrm{C}$, but as the depth of monomer in the tube was usually only about $50 \mathrm{~mm}$, the actual limits were considerably narrower. In some experiments a quartz plate of 2-mm thickness was fastened over the illumination slot. The plate was subject to rapid frosting, a difficulty not experienced in its absence because of the rapid outward flow of cold air.

From manufacturer's test data and dimensions of the apparatus, a very rough estimate can be made of the incident light intensity in various wavelengths; this is given in table 2. A calculation from the table shows that about $0.28 \mathrm{w}$ of illumination are received per centimeter of liquid depth, and that this illumination includes about $1.4 \times 10^{-5}$ einstein per minute $\left(1.4 \times 10^{5}\right.$ quanta per second) in wavelengths 1942 and $1849 \mathrm{~A}$, and $3.8 \times 10^{-5}$ einstein per minute in the wavelength $2537 \mathrm{~A}$.

$4.7 \times 10^{-3} \mathrm{w} \mathrm{cm}^{-2} \times 0.6 \mathrm{~cm} \times\left(\frac{100 \mathrm{~cm}}{10 \mathrm{~cm}}\right)^{2}=0.28 \mathrm{w} \mathrm{cm}^{-1}$. 
It is probable that most of this light in the lower wavelengths was absorbed by tube walls and scattered by polymer, and that very little was absorbed by monomer.

Conversion was determined by weighing the polymer, except in the dibromide additive experiments, where it was determined by residual gas volume. Most of the polymer products were warmed overnight at $105^{\circ} \mathrm{C}$ before being submitted for pyrolysis studies.

Special equipment used in a few experiments will be described under the appropriate heading.

\section{TABLE 2. Characteristics of light source \\ (Hanovia high-pressure mercury lamp, type $\mathrm{L}_{2}$ )}

Total radiation at $1 \mathrm{~m}_{-}$

Distance, lamp to sample.

4. $7 \mathrm{mw} \mathrm{cm}^{-2}$

Slit width.

Liquid depth

Distribution, percent of total:

$10 \mathrm{~cm}$

$0.6 \mathrm{~cm}$

2 to $5 \mathrm{~cm}$

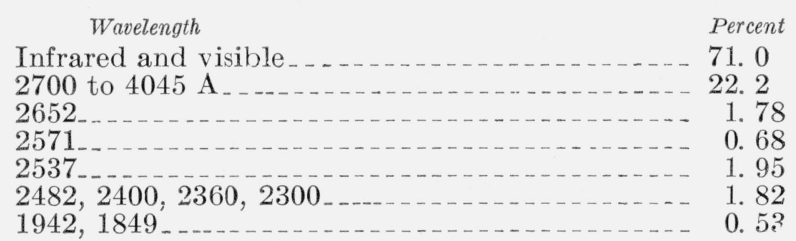

\subsection{Results}

The catalysts, conditions, and conversion to polymer are shown in tables 3, 4, and 5. Many of these polymerizations were found to proceed at temperatures as low as $-80^{\circ} \mathrm{C}$. Such temperatures are well known in Friedel-Crafts polymerizations, but are unusual in a free-radical catalyzed reaction. Schmitz and Lawton, however, have observed the polymerization of tetraethylene glycol dimethacrylate at $-55^{\circ}$ when the frozen monomer was irradiated with high-energy electrons and subsequently melted [14].

The photopolymerization of tetrafluoroethylene appears to proceed at a rather low rate, reproducible only as to order of magnitude. If we exclude experiment $5 \mathrm{~A}$, the rate shows a moderate irregular rise with temperature in the range $-85^{\circ}$ to $-40^{\circ} \mathrm{C}$. The effective wavelength for polymerization must be quite low, as is evident from the blocking effect of the quartz window (experiment 5A), as well as from the negative results of certain catalytic experiments in Vycor No. 790 (experiments 10, 17, 19), which transmits 2 to 4 percent in 2-mm thickness at 2,540 A [15]. This is reasonable in view of the absorption spectrum of the monomer, as shown in figure 1, curve 1 [16]. The values in this figure should be taken as suggestive only, since gas-phase data have been applied to liquid-phase conditions. The polymerization is probably not due to impurities, as the prolonged sodium and potassium treatment of monomer does not eliminate it. The anomalous high rate in experiments $5 \mathrm{~A}$ and $5 \mathrm{~B}$ is not fully understood. It may reflect an autocatalytic effect of preformed polymer, such as was found by Atkinson [3] in gasphase work; this possibility is also implicit in warn- ings by the du Pont Company on handling of the monomer. Such a phenomenon would, of course, throw great uncertainty into all rates reported here.

TABLE 3. Photopolymerization of tetrafluoroethylene

\begin{tabular}{|c|c|c|c|c|c|}
\hline $\begin{array}{c}\text { Experi- } \\
\text { ment }\end{array}$ & $\begin{array}{l}\text { Tempera- } \\
\text { ture }\end{array}$ & Time & $\begin{array}{l}\text { Conver- } \\
\text { sion }\end{array}$ & Rate & $\begin{array}{c}\text { Special } \\
\text { conditions }\end{array}$ \\
\hline $\begin{array}{l}1 \\
2 \\
3 \\
4 \\
5 \mathrm{~A} \\
5 \mathrm{~B} \\
6\end{array}$ & $\left\{\begin{array}{l}{ }^{\circ} \mathrm{C} \\
-75 \\
-75 \\
-75 \\
-75 \\
-40 \\
-50 \\
-70 \\
-85 \\
-80 \\
-80 \\
-80 \\
+30\end{array}\right.$ & $\begin{array}{r}\min \\
45 \\
70 \\
90 \\
120 \\
45 \\
50 \\
90 \\
240 \\
60 \\
158 \\
158 \\
1 \mathrm{mo}\end{array}$ & $\begin{array}{c}\% \\
<1 \\
\approx 10 \\
\approx 20 \\
19 \\
17 \\
22.3 \\
\approx 1 \\
16 \\
<1 \\
66.5 \\
66.5 \\
0\end{array}$ & $\begin{array}{c}\% / \mathrm{min} \\
0.16 \\
.38 \\
.45 \\
<.067 \\
.42 \\
.42 \\
0\end{array}$ & $\begin{array}{l}\mathrm{aq}^{1} \\
\mathrm{aq} \\
\mathrm{aq} \\
\mathrm{aq} \\
\mathrm{t} \\
\mathrm{t} \\
\text { aqs } \\
\text { aqs } \\
\text { nqw } \\
\text { anq } \\
\text { afnq } \\
\mathrm{d}\end{array}$ \\
\hline
\end{tabular}

${ }^{1} \mathrm{a}$, Time and rate are cumulative from beginning of experiment.

d, Dark; no illumination.

f, Polymer given special fluorine treatment.

$n$, Monomer pretreated with sodium mirror.

q, Thin-walled quartz tube.

s, Monomer from sodium perfluoropropionate, pretreated with potassium mirror.

$\mathrm{t}$, Thick-walled quartz tube.

w, $2-\mathrm{mm}$ quartz window.

At first sight, a comparison of experiments 4 and 1 suggests that the potassium-treated monomer derived from sodium perfluoropropionate may polymerize somewhat more slowly that the untreated monomer derived from Teflon; but the difference is hardly more than twofold, and is not established with certainty because of the difference in temperatures. Because of the occurrence of photopolymerization, and the relatively low rates of catalytic polymerization often observed, it is sometimes difficult to decide whether a given catalyst actually did have a catalytic effect.

Diperfluoromethylmercury. This catalyst is expected to dissociate into trifluoromethyl radicals and free mercury, and might be expected to lead to a completely saturated pure fluorocarbon polymer.

$$
\begin{aligned}
\left(\mathrm{CF}_{3}\right)_{2} \mathrm{Hg} \longrightarrow & 2 \mathrm{CF}_{3} \bullet+\mathrm{Hg} \\
\mathrm{CF}_{3} \cdot+n \mathrm{C}_{2} \mathrm{~F}_{4} & \longrightarrow \mathrm{CF}_{3}\left(\mathrm{C}_{2} \mathrm{~F}_{4}\right)_{n} \cdot \\
2 \mathrm{CF}_{3}\left(\mathrm{C}_{2} \mathrm{~F}_{4}\right)_{n} \bullet & \longrightarrow \mathrm{CF}_{3}-\left(\mathrm{C}_{2} \mathrm{~F}_{4}\right)_{n}-\left(\mathrm{C}_{2} \mathrm{~F}_{4}\right)_{n}-\mathrm{CF}_{3}
\end{aligned}
$$

Actually, the absorption spectrum of the mercury compound is not very favorable for photochemical decomposition. A comparison of absorption spectra, figure 1 , shows that diperfluoromethylmercury absorbs appreciably at wavelengths only a little longer than tetrafluoroethylene, both substances absorbing little light nearly down to the limit of transmission of quartz. Photopolymerization may compete with the catalyzed polymerization. The difficulty is increased by the very low solubility of this catalyst in the monomer. No polymerization occurred in Vycor, which is reasonable in view of the absorption spectrum of the catalyst and the transmission limits of Vycor. The Vycor No. 790 tube containing the sample was subsequently stored 1 month at $-20^{\circ} \mathrm{C}$, without further change. In experiments 7,8 , and 9 
TABLE 4. Catalytic photoactivated polymerization of tetrafluoroethylene

\begin{tabular}{|c|c|c|c|c|c|c|c|c|c|c|}
\hline $\begin{array}{c}\text { Experi- } \\
\text { ment }\end{array}$ & Catalyst & $\begin{array}{l}\text { Catalyst } \\
\text { concen tra- } \\
\text { tion } 1\end{array}$ & $\begin{array}{l}\text { Monomer } \\
\text { weight }\end{array}$ & $\begin{array}{l}\text { Tempera- } \\
\text { ture }\end{array}$ & Time & Conversion & Rate & $\begin{array}{c}\text { Special } \\
\text { conditions } 1\end{array}$ & \multicolumn{2}{|c|}{$\begin{array}{l}\text { Relative } \\
\text { rate }(\mathrm{h})^{1}\end{array}$} \\
\hline $\begin{array}{r}7 \\
8 \\
9 \\
10 \\
11\end{array}$ & 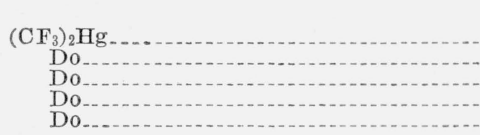 & $\begin{array}{ll}\text { Mole } \% & \\
0.05 & \text { i } \\
.244 & \text { i } \\
1.37 & \text { i } \\
0.29 & \text { i } \\
.124 & \text { i }\end{array}$ & $\begin{array}{l}g \\
5.38 \\
2.94 \\
\text { 4. } 40 \\
\text { 5. } 0 \\
\text { 4. } 12\end{array}$ & $\begin{array}{r}C \\
-80 \\
-80 \\
-80 \\
-22 \\
-50\end{array}$ & $\begin{array}{r}\min \\
120 \\
40 \\
>30 \\
240 \\
25\end{array}$ & $\begin{array}{l}\% \\
84 \\
89 \\
94 \\
0 \\
\quad 3.4\end{array}$ & $\begin{array}{r}\% / \min \\
0.7 \\
2.2 \\
<3.1 \\
0 \\
0.14\end{array}$ & $\begin{array}{l}\mathrm{q} \\
\mathrm{q} \\
\mathrm{q} \\
\mathrm{rv} \\
\mathrm{q}\end{array}$ & $\begin{array}{r}4 \\
14 \\
<19 \\
0 \\
.3\end{array}$ & $\begin{array}{l}\text { (1) } \\
\text { (1) } \\
\text { (3) }\end{array}$ \\
\hline $\begin{array}{l}12 \\
13 \\
14 \\
15 \\
16\end{array}$ & 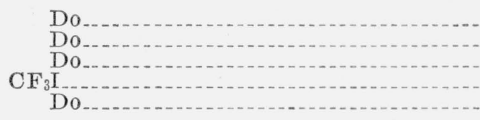 & $\begin{array}{ll}. & 163 \text { i } \\
.246 & \text { i } \\
.180 & \text { i } \\
.387 & \\
2 . & 32\end{array}$ & $\begin{array}{l}\text { 3. } 11 \\
\text { 2. } 23 \\
\text { 2. } 96 \\
\text { 2. } 61 \\
\text { 4. } 60\end{array}$ & $\begin{array}{l}-50 \\
-50 \\
-50 \\
-80 \\
-80\end{array}$ & $\begin{array}{l}25 \\
25 \\
25 \\
45 \\
80\end{array}$ & $\begin{array}{r}3.5 \\
5.7 \\
4.1 \\
16 \\
25.5\end{array}$ & $\begin{array}{r}.14 \\
0.36 \\
.32\end{array}$ & $\begin{array}{l}\text { q } \\
q r \\
q r \\
q w \\
q w\end{array}$ & $\begin{array}{r}-3 \\
>18 \\
>16\end{array}$ & $\begin{array}{r}(3) \\
(5 \mathrm{~A}) \\
(5 \mathrm{~A})\end{array}$ \\
\hline $\begin{array}{l}17 \\
18 \\
19 \\
20\end{array}$ & $\begin{array}{l}\text { Benzoyl peroxide } \\
\text { Do } \\
t \text {-Butyl peroxide } \\
\text { Azo-bis (isobutyronitrile) } \\
\mathrm{F}_{2}\end{array}$ & $\begin{array}{ll}0.352 & \mathrm{i} \\
.352 & \mathrm{i} \\
1.87 & \\
0.5 & \mathrm{i} \\
2.2 & \mathrm{~g}\end{array}$ & $\begin{array}{l}\text { 5. } 84 \\
5.84 \\
3.78 \\
5.0 \\
5.0\end{array}$ & $\begin{array}{l}-25 \\
-25 \\
-50 \\
-80 \\
-130\end{array}$ & $\begin{array}{r}95 \\
215 \\
80 \\
240 \\
25\end{array}$ & $\begin{array}{c}\text { Trace } \\
3.8 \\
31.8 \\
0 \\
\text { Trace }\end{array}$ & $\begin{array}{l}0.02 \\
. .40 \\
0\end{array}$ & $\begin{array}{l}\text { rv } \\
\text { qw } \\
\text { rv } \\
\text { bd }\end{array}$ & $\begin{array}{c}\infty \\
> \\
20 \\
0 \\
---\end{array}$ & $\begin{array}{r}(10) \\
(5 \mathrm{~A}) \\
(10)\end{array}$ \\
\hline $\begin{array}{l}21 \\
22\end{array}$ & 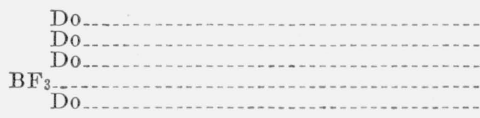 & $\begin{array}{ll}2.2 & \mathrm{~g} \\
17 & \\
17 & \\
0.27 & \\
1.52 & \end{array}$ & $\begin{array}{l}\text { 5. } 0 \\
5.0 \\
5.0 \\
\text { 3. } 75 \\
4.51\end{array}$ & $\begin{array}{r}-80 \\
-130 \\
-80 \\
+30 \\
+30\end{array}$ & $\begin{array}{r}35 \\
50 \\
57 \\
>6 \mathrm{mo} \\
>1 \mathrm{yr}\end{array}$ & $\begin{array}{r}\approx \\
\approx \\
\approx \\
0 \\
0\end{array}$ & $\begin{array}{c}0.5 \\
0 \\
0\end{array}$ & $\begin{array}{l}\mathrm{bd} \\
\mathrm{bd} \\
\mathrm{bd} \\
\mathrm{d} \\
\mathrm{d}\end{array}$ & \begin{tabular}{l}
-.2 \\
\hdashline 3.2 \\
0 \\
0
\end{tabular} & (1) \\
\hline
\end{tabular}

$1 \mathrm{~b}$, Time is cumulative from beginning of experiment, rate average of last two periods.

d, Dark; no illumination.

$\mathrm{g}$, Catalyst concentration in bubbled gas.

$\mathrm{h}$, Figure in parentheses shows number of photopolymerization experiment used for comparison.

i, Catalyst nearly insoluble.
q, Thin-walled quartz tube.

r, Subsequent storage appeared to give no change; see text for details.

$\mathrm{v}$, Vycor tube and $2-\mathrm{mm}$ quartz window.

w, 2-mm quartz window.

TABLE 5. Additives in photoactivated polymerization of tetrafuoroethylene

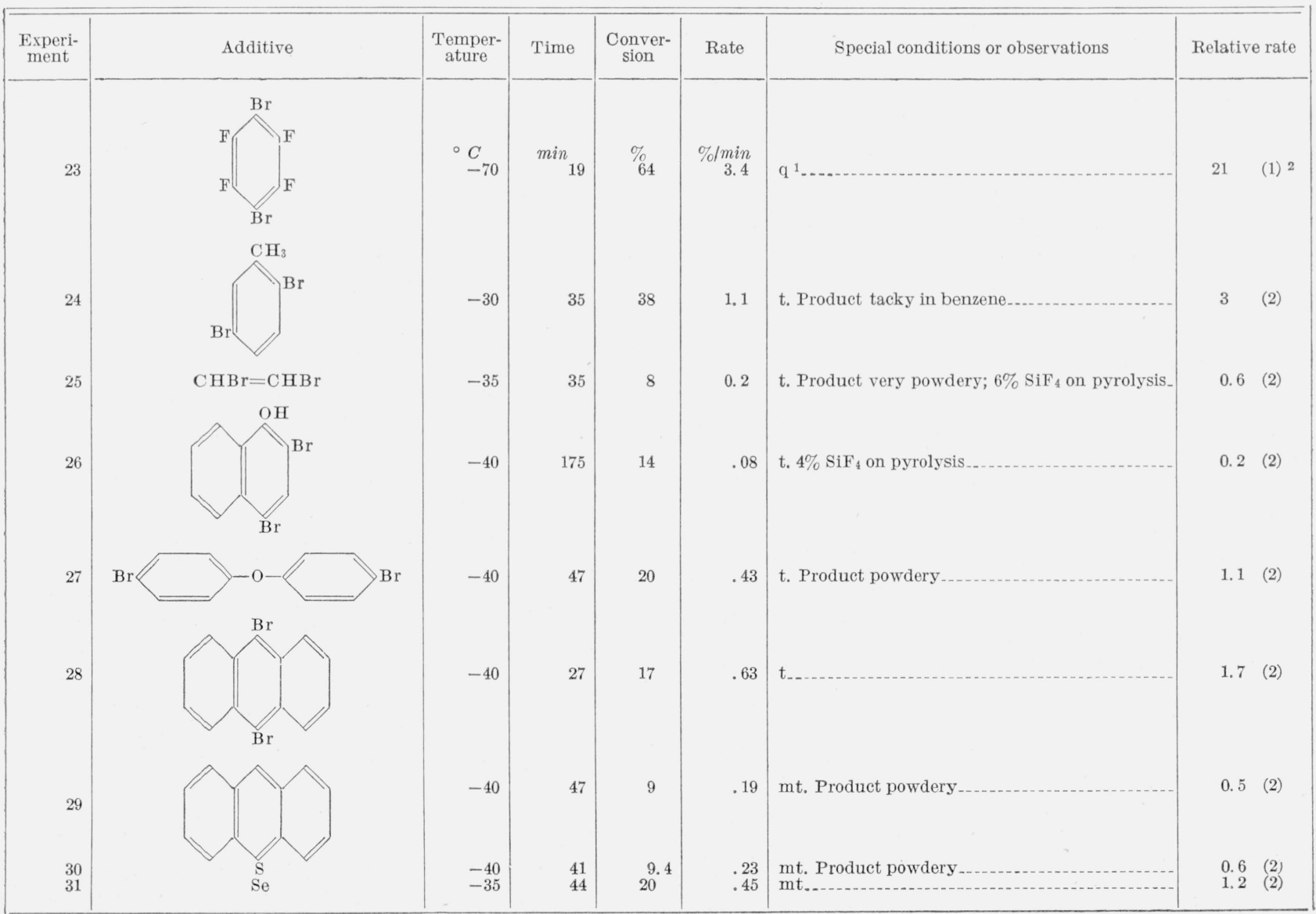

1 q, Thin-walled quartz tube.

$\mathrm{t}$, Thick-walled quartz tube.

$\mathrm{m}$, Additive applied as mirror.

2 Figure in parentheses shows number of photopolymerization experiment used for comparison. 


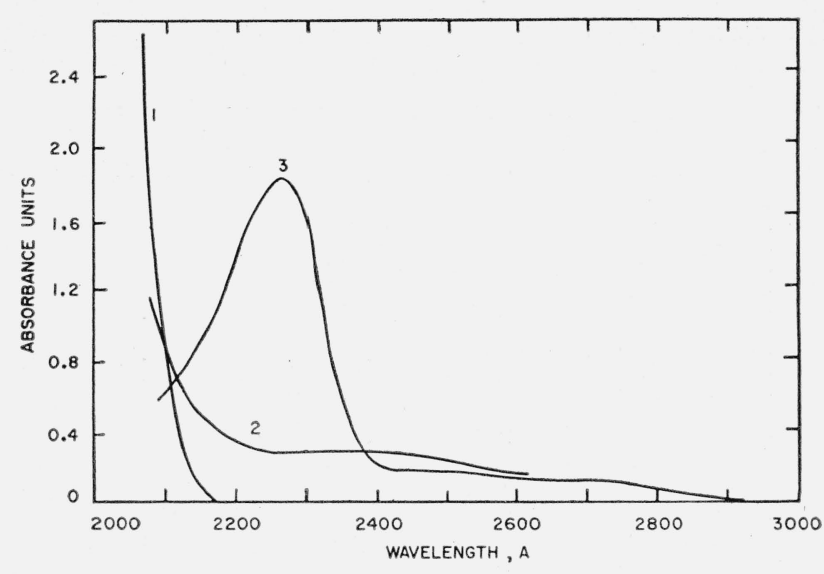

Figure 1. Absorption spectra.

Curve 1, $\mathrm{C}_{2} \mathrm{~F}_{4}$, molar absorbance $\epsilon$; curve $2,\left(\mathrm{CF}_{3}\right)_{2} \mathrm{Hg}$, absorbance of qualitative dilute solution in ethanol; curve $3, \mathrm{C}_{6} \mathrm{~F}_{4} \mathrm{Br} 2$, molar absorbance $\epsilon \times 10^{-4}$.

the rates seem to be much higher than photopolymerization and seem to increase with concentration of catalyst. However, the results are from samples that have proceeded to nearly 100-percent conversion and may also reflect autocatalysis by polymer. If the variation with catalyst amount is significant, it may be explicabla by a process of continual replacement of catalyst in the saturated solutions.

The four experiments $11,12,13$, and 14 were undertaken to determine whether the diperfluoromethylmercury catalyzed polymerization can continue in the dark for appreciable periods after being started photochemically. All four samples were illuminated for identical periods at $-50^{\circ} \mathrm{C}$. Samples 11 and 12 were opened immediately; 13 and 14 were stored in the dark for 1 month at $-20^{\circ} \mathrm{C}$. The stored samples seem to show a slightly higher conversion. The difference is probably not significant; the subsequent dark polymerization, if any, is certainly slight. The rates seem low for $-50^{\circ}$, by comparison with experiments 7,8 , and 9 and the photopolymerization experiment 3 .

Iodotrifluoremethane. Haszeldine [17], using large quantities of iodotrifluoromethane with tetrafluoroethylene, and activation by heat $\left(200^{\circ} \mathrm{C}\right)$, ordinary light, and ultraviolet, obtained solid telomers containing many $\mathrm{C}_{2} \mathrm{~F}_{4}$ units per $\mathrm{CF}_{3} \mathrm{I}$ residue. Extrapolating from his results, we would expect only a very small proportion of $\mathrm{CF}_{3} \mathrm{I}$ derived material in the present products. There was no gross appearance of iodine in the polymer, as would be necessary if large amounts of iodotrifluoromethane were consumed and pure fluorocarbon polymer formed. The pyrolysis of the polymer did not show iodine or iodine-containing fragments; the amounts may have been too small for detection in a telomer of very high molecular weight. The rates of polymerization are about alike over a sixfold variation of iodotrifluoromethane concentration, which suggests compensating increases in initiation and termination. Higher rates than these might have been expected from the strong absorption by iodotrifluoromethane, which has a maximum at 2,680 $\mathrm{A}$ [18].
Peroxides and azo-bis(isobutyronitrile). Benzoyl peroxide brought about a very slow polymerization in Vycor at the rather high temperature of $-25^{\circ}$ C. This is to be compared, however, with the total lack of polymerization when diperfluoromethylmercury is used (and therefore also in a pure blank). Storage at $-20^{\circ} \mathrm{C}$ for 1 month did not appear to. increase the yield; thermal activation of the catalyst. and continuation of the reaction by frozen-in free radicals were therefore negligible.

Di-t-butyl peroxide brought about a reasonably rapid polymerization at $-50^{\circ} \mathrm{C}$. The corresponding photopolymerization rate should be the very low rate experienced when a quartz window is added (experiment 5A).

Azo-bis(isobutyronitrile) did not cause any polymerization is Vycor at $-80^{\circ} \mathrm{C}$. The transmission of Vycor should not be responsible for this failure because the catalyst is known to be activated by light of the order of $3,600 \mathrm{~A}$ [19] when used with other monomers. It is possible that radicals from this catalyst are not sufficiently active to initiate polymerization of tetrafluorethylene, at least at the temperature of $-80^{\circ} \mathrm{C}$.

Fluorine. The action of free fluorine upon most organic compounds is known to cause complicated free-radical chain reactions, and it was found alsoto initiate polymerization of tetrafluoroethylene at low temperatures. Liquid fluorocarbons were also formed. The polymer product also contained some strongly held silicon tetrafluoride; its generally complicated composition created uncertainties in the subsequent pyrolysis studies. Fluorine gas diluted with helium was bubbled through monomer in Pyrex equipment, immersed in a freezing pentane slush, and subsequently in a dry-ice bath. Little solid product was formed with very dilute fluorine; a moderately rapid formation of solid polymer was. observed with a higher concentration containing 17 percent of fluorine. At $-80^{\circ} \mathrm{C}$ evaporation led to rapid losses of monomer. Impurities in the tank fluorine, which are not readily removable, such as oxygen fluoride, could have affected the reaction and the structure of the product. Refinements in equipment, higher catalyst purity, and more ideal conditions might lead to the desired type of saturated pure fluorocarbon polymer.

Boron trifluoride. Boron fluoride was reported by Von Grosse and Cady [7] to cause the slow polymerization of tetrafluoroethylene at room temperature to a solid polymer resembling Teflon. In the present study two concentrations were prepared in Pyrex tubes and left for periods of 6 to 18 months. No change was observed. Although boron fluoride is known to require a co-catalyst such as water in order to be catalytically active, the requisite traces of water are always present unless removed by a technique much more stringent than that employed here [20]; therefore, it is believed that boron fluoride is inactive, and that Von Grosse and Cady's polymerization was due to adventitious oxygen. Their polymerization with niobium pentafluoride cannot be explained in this fashion, and possibly other catalytic metal fluorides exist. 
Polymerizations with added components. The technique was simplified in that approximate $0.1-\mathrm{g}$ quantities of the added component were used without measurement, with about $5 \mathrm{~g}$ of monomer measured by pressure and volume. Most of these added components were nearly insoluble; some were applied as mirrors. Many of these materials affected the polymerization rate considerably. As little is known of high-temperature inhibition, there are few guiding principles except the obvious one that the inhibiting group should be capable of at least a short existence at about $400^{\circ}$ to $500^{\circ} \mathrm{C}$. Many dibromides were chosen, since it appeared likely that the structural group might be incorporated into a fluorocarbon polymer by removal of bromine, either photochemically or by free radicals. It is still uncertain to what extent the added groups were incorporated in the polymer structure; that this extent was probably small is likely from their failure to appear among pyrolysis products.

For dibromotetrafluorobenzene the absorption spectrum (fig. 1) shows considerable absorption in the range 2,900 to below $2,100 \mathrm{~A}$, with a molar absorbance $\epsilon=18,400$ at the maximum of $2,275 \mathrm{~A}$.

Under exposure to ultraviolet light the dibromo compound alone and in perfluorotriethylamine solution appears to react very slowly; in 12 hours a slight brown color and an odor of bromine were noted, and nearly all the material was recovered unchanged. The mass-spectrometer pattern does not indicate that the bromine atoms or any others are especially labile; however, the compound will undergo Wurtztype condensations at about $300^{\circ} \mathrm{C}$ [21]. The polymerization of tetrafluoroethylene with added dibromotetrafluorobenzene was more rapid at $-80^{\circ} \mathrm{C}$ than any of the other catalytic polymerizations at any temperature. Unpolymerized volatile material contained 95.(6) percent of $\mathrm{C}_{2} \mathrm{~F}_{4}, 3.9$ percent of $\mathrm{C}_{3} \mathrm{~F}_{6}$, and 0.5 percent of $\mathrm{SiF}_{4}$, as well as traces of fluorocarbons up to $\mathrm{C}_{4}$. Because the dibromotetrafluorobenzen decomposes quite slowly alone and its presence in the polymer in substantial amount was not proved, the material may possibly act merely by efficient transfer of energy to the monomer, by a process loosely analogous to that occurring in mercury-sensitized photodecompositions.

The other dibromides were less-spectacular promoters. Dibromotoluene showed a smaller acceleration; dibromoethylene, dibromodiphenyl ether, and dibromoanthracene had little or no effect, the first of these being perhaps a mild retarder; and dibromoalpha-naphthol was a powerful retarder. The nonpolymeric residue from the latter material contained perfluoro-olefins up to $\mathrm{C}_{8}$, with no volatile bromine compounds or partially fluorinated compounds. Of the others, anthracene and sulfur were probably mild retarders, and selenium did not appreciably affect the rate. Possibly with dibromides of the hydrocarbon type, photochemical dissociation of the $\mathrm{C}-\mathrm{Br}$ bond brings about a more rapid initiation, which accounts for observed promoter action; but parallel with this, there may be a transfer reaction of the fluorocarbon polymer radical to abstract hydrogen from $\mathrm{C}-\mathrm{H}$ bonds. If the resulting hydrocarbon radical is reactive, ordinary transfer results; if unreactive, an effective retardation.

If the retardation by sulfur is real here, it may be due to addition of a fluorocarbon free radical to sulfur to form a stable radical of similar formula to those postulated in the explanation of mercaptan retardation.

\section{Discussion of Pyrolyses}

\subsection{General Considerations}

A few important points concerning the thermal decomposition of tetrafluoroethylene polymers were mentioned in the introduction. One of the prime considerations governing thermal stability is the strength of the bonds in the molecule. In this respect tetrafluoroethylene should be outstanding. The $\mathrm{C}-\mathrm{C}$ bond, which forms the backbone of the chain, is one of the strongest single bonds capable of forming large molecules, and the $\mathrm{C}-\mathrm{F}$ bond is much stronger [22]. There is some evidence that the $\mathrm{C}-\mathrm{C}$ bond in fluorocarbons may have a higher strength than the value given. Exact thermochemical data from which to compute bond energies are lacking for fluorocarbons, but electron-impact data indicate a value of $124 \mathrm{kcal}$ for the dissociation. energy of the $\mathrm{C}-\mathrm{C}$ bond in fluorocarbons, as against only 79 to $83 \mathrm{kcal}$ for this bond in paraffin hydrocarbons [23, 241]. (Although these bond dissociation energies are not equivalent to the bond energies derived thermochemically, they are perhaps more pertinent to the question of thermal decomposition.)

From the standpoint of the bond energies in analogous low-molecular-weight compounds, the actual thermal behavior of polytetrafluoroethylene is disappointing. Polyethylene decomposes appreciably, 0.16 percent per minute at $385^{\circ} \mathrm{C}$; polytetrafluoroethylene decomposes at the same rate at $489^{\circ}$ C, only $104 \mathrm{deg}$ higher [9, 25]. For comparison, bond-dissociation energies in related simple molecules are: for $\mathrm{C}_{2} \mathrm{H}_{6}$ and other lower paraffins, $\mathrm{C}-\mathrm{C}=80$ kcal, $\mathrm{C}-\mathrm{H}=101 \mathrm{kcal}$; for $\mathrm{C}_{2} \mathrm{~F}_{6}, \mathrm{C}-\mathrm{C}=124 \mathrm{kcal}$, $\mathrm{C}-\mathrm{F}=107 \mathrm{kcal}$. All figures except $\mathrm{C}-\mathrm{F}$ are derived from electron-impact data.

It is evident that the correlation between bond energies and thermal stability is only rough and imperfect; a more direct insight is to be found in the detailed kinetics of pyrolysis. A large number of vinyl polymers, including polytetrafluoroethylene, decompose thermally by a depolymerization with splitting of the polymer chain. Others, with which we are not concerned here, decomposed by stripping off side groups from the carbon chain. A comprehensive theory of thermal depolymerization has been developed by Wall, Simha, and others [26, 27] and special cases in partially equivalent forms by Jellinek [28] and by Grassie and Melville [29], and it has been the subject of extensive experimental investigation. The elementary processes, according to this theory, are: (1) initiation, by which free radicals are formed, (2) depropagation or "unzipping," in which successive monomer units are broken off from these free 
radicals, (3) transfer, in which one radical is stabilized and a new one formed, and (4) termination, destroying two radicals.

Initiation:

$\sim \mathrm{CX}_{2} \mathrm{CX}_{2} \mathrm{CX}_{2} \mathrm{CX}_{2} \sim \longrightarrow \sim \mathrm{CX}_{2} \mathrm{CX}_{2} \cdot+\sim \mathrm{CX}_{2} \mathrm{CX}_{2}$

or

$$
\mathrm{Y}-\mathrm{CX}_{2} \mathrm{CX}_{2} \sim \mathrm{Y} \cdot+\sim \mathrm{CX}_{2} \mathrm{CX}_{2}
$$

(De)propagation:

$\sim \mathrm{CX}_{2} \mathrm{CX}_{2} \mathrm{CX}_{2} \mathrm{CX}_{2} \cdot \longrightarrow \sim \mathrm{CX}_{2} \mathrm{CX}_{2} \cdot+\mathrm{CX}_{2}=\mathrm{CX}_{2}$

Transfer:

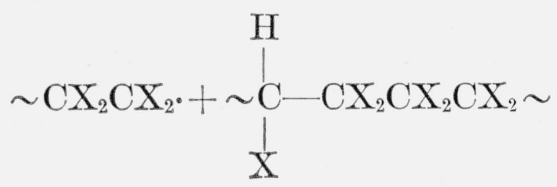

$$
\longrightarrow \sim \mathrm{CX}_{2} \mathrm{CX}_{2} \mathrm{H}+\sim \mathrm{CX}=\mathrm{CX}_{2}+\cdot \mathrm{CX}_{2} \mathrm{CX}_{2} \sim
$$

Termination:

$$
2 \sim \mathrm{CX}_{2} \mathrm{CX}_{2} \cdot \longrightarrow \sim \mathrm{CX}=\mathrm{CX}_{2}+\sim \mathrm{CX}_{2} \mathrm{CX}_{2}
$$

The resulting rate equations are tractable for certain cases, though not simple, and for chosen values of the rate constants or their ratios, curves can be constructed to show the course of monomer vield, total volatile products, and molecular weight of residue during depolymerization.

It may be noted that the initiation step can occur either at an ordinary $\mathrm{C}-\mathrm{C}$ bond (eq 1a) or at a much weaker bond (eq 1b), which can be present in. a catalyst fragment, a foreign group present in the chain, or even in a separate molecule of some contaminant, such as unreacted catalyst. If many of these labile centers of initiation are present, the stability of the polymer may be greatly reduced. A spectacular example is the case of polymethylmethacrylate; this polymer when prepared photochemically with diphenylcyanomethyl end- groups, decomposes slowly at $280^{\circ} \mathrm{C}$, but when prepared with large amounts of benzoyl peroxide catalyst, will decompose more rapidly at a temperature 40 deg lower [29].

It may also be noted that, depending upon circumstances and the character of the polymer, the depropagation reaction may proceed through few or many stages before being interrupted by transfer or termination. In impure mixtures, still other types of interruption are conceivable. The free radical may lose monomer units until a structural irregularity in the chain is reached, from which further loss is difficult; or it may react with foreign molecules to produce stable products. The latter type of interruption of free-radical reactions is well known in the allied fields of polymerization and oxidation, but does not seem to have been found thus far in high-temperature depolymerization, although inhibition with nitric oxide is well known in gas-phase systems at these temperatures [29].

In the case of polytetrafluoroethylene the structure offers no opportunity for transfer reactions, and the product of pyrolysis is nearly pure monomer. Initiation may be difficult, except at thermally labile endgroups derived from the catalyst. The solid or highly viscous state of the material undergoing pyrolysis may render the free radicals immobile and inacessible to most reactions except depropagation. This circumstance may greatly extend the lifetime of the radicals, and thus increase the rate of decomposition.

Such considerations made it plausible (a) that available preparations of polytetrafluoroethylene might not be the most stable possible, and (b) that even the purest polytetrafluoroethylene might be less stable than preparations containing suitable structural irregularities or foreign additives.

\subsection{Results of Pyrolyses}

The pyrolysis data given in table 6 are from the work of Madorsky, Hart, Straus, and Sedlak, full details of which are included in their report [9]. The product of pyrolysis was nearly pure tetrafluoroehylene. Catalyst and additive fragments were not found, except for occasional hydrocarbon peaks (in the mass spectrometer), which may have been background, and occasional percentages of silicon tetrafluoride above the normal trace, which may or may not have been due to liberation of hydrogen fluoride from hydrogen-containing fragments. Extrapolated initial rates are quoted, but any other basis would have served as well, since the data of any individual experiment fitted a first-order rate curve closely over practically the whole course of the decomposition, an

\begin{tabular}{|c|c|c|c|c|}
\hline Sample 1 & Temperature & Initial rate & $\begin{array}{c}\text { Rate for Teflon } \\
\text { at temperature } \\
\text { shown }\end{array}$ & $\begin{array}{l}\text { Ratio, or rela- } \\
\text { tive rate }\end{array}$ \\
\hline $\begin{array}{l}1 \\
5 \mathrm{~B} \\
3 \\
8 \\
9\end{array}$ & $\begin{array}{l}{ }^{\circ} \mathrm{C} \\
497 \\
501 \\
513 \\
490 \\
460\end{array}$ & $\begin{array}{c}\% / \min \\
0.400 \\
.428 \\
1.074 \\
0.219 \\
.026\end{array}$ & $\begin{array}{c}\% / \min \\
0.305 \\
.403 \\
1.059 \\
0.185 \\
.019\end{array}$ & $\begin{array}{l}\text { 1. } 31 \\
1.06 \\
1.015 \\
1.083 \\
1.37\end{array}$ \\
\hline $\begin{array}{l}9 \\
9 \\
9 \\
9 \\
9\end{array}$ & $\begin{array}{l}470 \\
480 \\
490 \\
500 \\
510\end{array}$ & $\begin{array}{l}.054 \\
.111 \\
.225 \\
.444 \\
.840\end{array}$ & $\begin{array}{l}.042 \\
.089 \\
.185 \\
.375 \\
.755\end{array}$ & $\begin{array}{l}1.28 \\
1.25 \\
1.22 \\
1.18 \\
1.11\end{array}$ \\
\hline $\begin{array}{l}15 \\
16 \\
17 \\
18 \\
20\end{array}$ & $\begin{array}{l}502 \\
496 \\
498 \\
494 \\
470\end{array}$ & $\begin{array}{l}.356 \\
.235 \\
.442 \\
.245 \\
.0469\end{array}$ & $\begin{array}{l}.436 \\
.284 \\
.328 \\
.245 \\
.0419\end{array}$ & $\begin{array}{r}0.82 \\
.79 \\
1.35 \\
1.00 \\
1.12\end{array}$ \\
\hline $\begin{array}{l}20 \\
23 \\
24 \\
24 \\
25\end{array}$ & $\begin{array}{l}450 \\
513 \\
513 \\
450 \\
513\end{array}$ & $\begin{array}{l}.0158 \\
1.109 \\
0.716 \\
.0171 \\
.961\end{array}$ & $\begin{array}{l}.0132 \\
1.059 \\
1.059 \\
0.0146 \\
1.059\end{array}$ & $\begin{array}{l}1.20 \\
1.05 \\
0.68 \\
1.17 \\
0.91\end{array}$ \\
\hline $\begin{array}{l}26 \\
27 \\
28 \\
29 \\
31\end{array}$ & $\begin{array}{l}513 \\
513 \\
513 \\
513 \\
513\end{array}$ & $\begin{array}{l}1.244 \\
0.964 \\
.929 \\
1.032 \\
0.902\end{array}$ & $\begin{array}{l}1.059 \\
1.059 \\
1.059 \\
1.059 \\
1.059\end{array}$ & $\begin{array}{r}1.17 \\
0.91 \\
.88 \\
.97 \\
.85\end{array}$ \\
\hline
\end{tabular}
unusual occurrence in the pyrolysis of high polymers.

TABLE 6. Pyrolysis of tetrafluoroethylene polymers

1 Sample numbers refer to polymers obtained in the corresponding numbered experiments in tables 3,4 , and 5 . 
The first few minutes of pyrolysis, representing from a fraction of a percent to a few percent decomposition, are obscured because of the heating-up period before constant temperature is reached. This uncertain period is about 5 minutes in most experiments, but probably only 2 minutes in the experiments on samples 23 to 31. Experimental considerations made it most convenient to compared the rates of given samples with those of commercial Teflon at corresponding temperatures; this reference material showed highly consistent and reproducible behavior. In figure 2 the relation of initial rate and temperature for Teflon is shown as a solid line, and the rates for the special tetrafluoroethylene polymers are indicated by numbered points, the numbers referring to polymers in tables 3,4 , and 5 . These data are also given in table 6 .

It will be recalled from discussion of the mechanism of pyrolysis that the decomposition rate should be lowered by (a) replacing more labile end-groups by completely fluorinated saturated end-groups, which would decrease the formation of free radicals; (b) incorporating inhibitors, which would react with the radicals as soon as formed, for a limited period; or (c) incorporating hydrogen-containing groups, which would give rise to cross linking as a competing reaction besides depropagation. In the third case, a drop in molecular weight could occur, but the material would still remain polymeric.
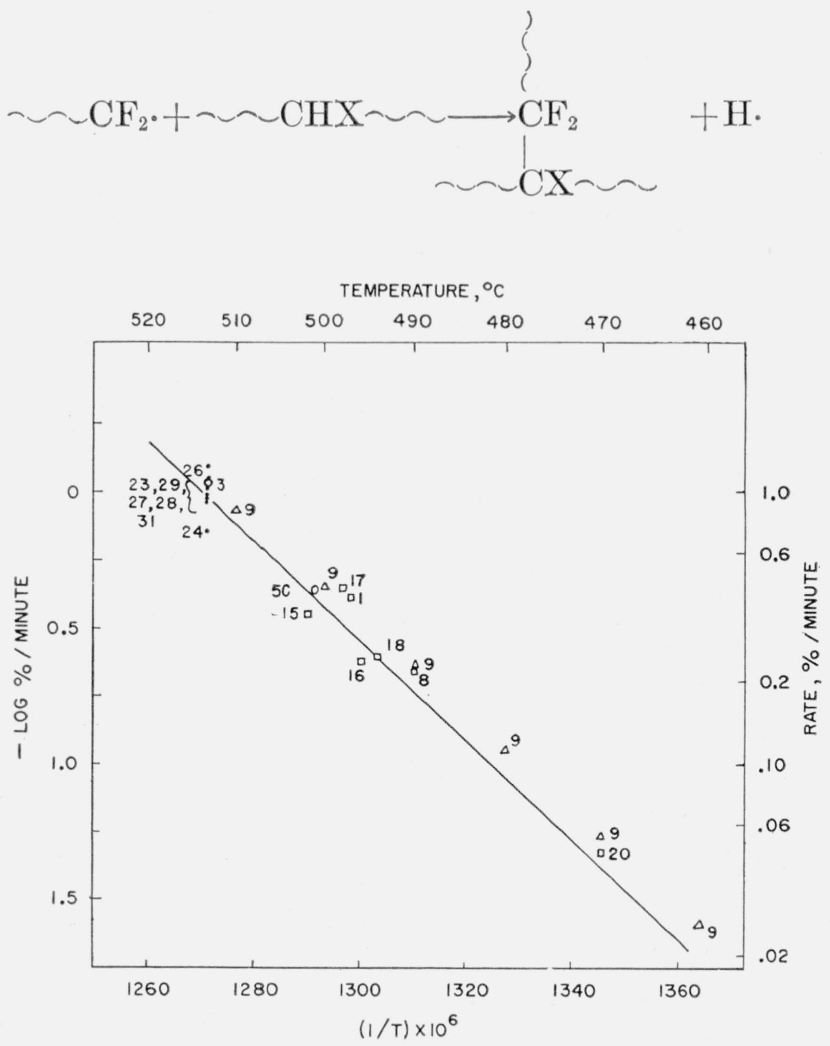

FIgURe 2. Pyrolysis of various tetrafluoroethylene polymers.

___ reference curve, commercial Teflon; $\bigcirc$ photopolymers; $\triangle$, $\square$, catalytic polymers; ·, polymers with additives. Numbers refer to samples in tables 3,4 , and 5.
The most striking experimental generalization is that none of the products differed greatly from ordinary Teflon in pyrolysis rate. The small differences that did occur are probably less than the experimental error. Possibly in all products, including Teflon, most of the labile groups were removed long before the pyrolysis temperature was reached, to form fairly stable olefinic end-groups. For example,

$$
\frown \frown \mathrm{CF}_{2} \mathrm{CF}_{2} \mathrm{CO}_{2} \mathrm{H} \longrightarrow \sim \sim \mathrm{CF}=\mathrm{CF}_{2}+\mathrm{HF}+\mathrm{CO}_{2} \text {. }
$$

The photopolymers should be free from nonfluorocarbon groups but not necessarily saturated. Sample $5 \mathrm{~B}$, exposed to fluorine gas after polymerization, should be the most completely saturated photopolymer. Although one of the photopolymers listed in table 6 , No. 1 , decomposed with a relative rate of 1.3 , the other two were indistinguishable from Teflon in their behavior.

Samples 8 and 9 should have perfluoromethyl endgroups derived from diperfluoromethylmercury. They appeared to decompose at slightly higher rates than Teflon. The difference may be within experimental error; no explanation can be given for the lower stability, if real.

Samples made with iodotrifluoromethane appeared slightly more stable than Teflon; the stability did not depend upon the amount of iodotrifluoromethane used. If the polymer molecules contain C-I linkages (as Haszeldine's low telomers do), a lower rather than higher stability might have been expected because of the weaker $\mathrm{C}-\mathrm{I}$ bond. Perhaps the $\mathrm{C}$ - I bonds, or iodine atoms derived from them, encourage chain transfer.

The peroxide polymers, 17 and 18, might have been expected to be the least stable; actually, the $t$-butyl peroxide polymer was about normal, and the benzoyl peroxide polymer decomposed at a rate 1.35 times normal.

The polymer made with gaseous fluorine might be expected to have saturated fluorocarbon end-groups:

$$
\begin{gathered}
\mathrm{F}_{2} \longrightarrow 2 \mathrm{~F} \cdot \\
\mathrm{F} \cdot+\mathrm{CF}_{2}=\mathrm{CF}_{2} \longrightarrow \mathrm{CF}_{3} \mathrm{CF}_{2} \mathrm{a}
\end{gathered}
$$

With the very active fluorine atoms, side reactions such as $\mathrm{C}-\mathrm{C}$ bond splitting might also have been possible during polymerization, leading to lower molecular weight. The fluorine catalyzed polymer actually decomposed at about the normal rate. The experimental determination of rate was open to some objection, as large quantities of low-molecular-weight material and silicon tetrafluoride were evolved in early stages before a steady rate was observed.

The additives (23 to 31) might have served conceivably either as structural elements in the polymer chain, capable of acting as internal inhibitors or as cross-linking agents, or an inhibitors mechanically admixed with the polymer. Because of negative mass-spectrometer results, there is not much direct evidence that any of the additives were incorporated in the polymer chain in large amounts, except that the increased production of silicon tetrafluoride from 
the dibromoethylene sample 25 and the dibromo- $\alpha$ naphthol sample 26 may reflect evolution of hydrogen fluoride from adjacent $\mathrm{C}-\mathrm{H}$ bonds of the additive and $\mathrm{C}-\mathrm{F}$ bonds of the regular monomer sequence. The polymerization rate-results mentioned earlier do indeed suggest that the additives are involved in some fashion in the polymerization. Probably most of the dibromide additives, if not incorporated in the polymer chain, were sufficiently volatile to be eliminated from thin layers of polymer during the evacuation period preceding pyrolysis. The hydrocarbon groups derived from dibromides were expected to act as chain-transfer agents, tne tetrafluorobenzene group from dibromotetrafluorobenzene merely as a structural irregularity, with some likelihood of extra resonance stabilization. Of these materials 1, 2-dibromoethylene increased the pyrolysis rate somewhat, and the others were practically neutral.

It is evident that eliminating thermally labile end-groups and replacing with fluorocarbon endgroups did not greatly lessen the rate of pyrolysis of polytetrafluoroethylene. This result makes it plausible that in tetrafluoroethylene polymers generally, the initiation step occurs by breaking of fluorocarbon $\mathrm{C}-\mathrm{C}$ bonds rather than through some weaker bond derived from catalyst or impurity.

None of the chain-transfer agents seem to have produced observable reductions in pyrolysis rate. It may be possible to get observable effects by the use of aromatic rings containing many methyl groups. If we consider the unusual maintenance of a solid state during decomposition, it seems probable that, to be highly effective, a chain transfer agent or inhibitor should be capable of rapid diffusion in order to reach immobile free radicals in the polymer. The problem of maintaining such agents in a polymer at high temperatures might be solved by (a) a compromise between volatility and diffusion rates, or (b) the slow generation of such active agents within the polymer mass. Further work in these unexplored fields seems desirable.

Washington, December 18, 1953.

\section{References}

[1] R. J. Plunkett, U. S. Pat. 2,230,654.

[2] W. E. Hanford and R. M. Joyce, J. Am. Chem. Soc. 68, 2082 (1946).

[3] B. Atkinson, J. Chem. Soc. 1952, 2684.

[4] F. A. Raal and C. J. Danby, J. Chem. Soc. 1950, 1596.

[5] R. N. Haszeldine, J. Chem. Soc. 1950, 3041.

[6] K. L. Berry and J. H. Peterson, J. Am. Chem. Soc. 73, 5195 (1951).

[7] A. V. Grosse and G. H. Cady, Ind. Eng. Chem. 39, 367 (1947).

[8] E. E. Lewis and M. A. Naylor, J. Am. Chem. Soc. 69, 1968 (1947).

[9] S. L. Madorsky, V. E. Hart, S. Straus, and V. A. Sedlak, J. Research NBS 51, 327 (1953) RP2461.

[10] L. J. Hals, T. S. Reid, and G. H. Smith, J. Am. Chem, Soc. 73, 4054 (1951).

[11] R. N. Haszeldine, J. Chem. Soc. 1951, 584; A. L. Henne and W. G. Finnegan, J. Am. Chem. Soc. $7 \boldsymbol{2}, 3806$ (1950).

[12] H. J. Emeleus and R. N. Haszeldine, J. Chem. Soc. 1948, 2953.

[13] Max Hellmann and A. J. Bilbo, J. Am. Chem. Soc. 75, 4590 (1953).

[14] J. V. Schmitz and E. J. Lawton, Science 114, 718 (1951).

[15] Corning Glass Works Catalog LP24, p. 131.

[16] J. R. Lacher, L. E. Hummel, E. F. Bohmfalk, and J. D. Park, J. Am. Chem. Soc. \%,, 5486 (1950).

[17] R. N. Haszeldine, J. Chem. Soc. 1949, 2856.

[18] J. Banus, H. J. Emeleus, and R. N. Haszeldine, J. Chem. Soc. 1950, 3041 .

[19] M. S. Matheson, E. E. Auer, E. B. Bevilacqua, and E. J. Hart, J. Am. Chem. Soc. 71, 2610 (1949).

[20] A. G. Evans and G. W. Meadows, Trans. Faraday Soc. 46, 327 (1950); A. G. Evans, G. W. Meadows, and M. Polanyi, Nature 158, 94 (1946).

[21] M. Hellmann (unpublished work).

[22] L. Pauling, The nature of the chemical bond, $2 \mathrm{~d}$ ed., p. 52 (Cornell Uriiversity Press, Ithaca, N. Y., 1945).

[23] V. H. Dibeler, R. M. Reese, and F. L. Mohler, J. Chem. Phys. 20, 761 (1952).

[24] J. A. Hipple and D. P. Stevenson, Phys. Rev. 63, 121 (1943) and earlier papers; discussed in E. W. R. Steacie, Free radical mechanisms, p. 61 (Reinhold Publishing Co., New York, N. Y., 1946).

[25] S. L. Madorsky, J. Polymer Sci. 9, 133 (1952).

[26] Robert Simha, L. A. Wall, and P. J. Blatz, J. Polymer Sci. 5, 615 (1950).

[27] Robert Simha and L. A. Wall, J. Polymer Sci. 6, 39 (1951).

[28] H. H. G. Jellinek, J. Polymer Sci. 3, 850 (1945) ; 4, 113 (1949)

[29] N. Grassie and H. W. Melville, Proc. Roy. Soc. A199, 1, 14, 24 (1949). 